\title{
Metabolic risk factors detected among the attendees to free health camps conducted in Western province of Sri Lanka
}

\author{
S A S P Subasinghe ${ }^{1}$, C W Jayesundere ${ }^{1}$, Kanthi Piyaseeli ${ }^{1}$, P A Epa $^{1}$, Nirmanee Gamage $^{1}$, Priyanga \\ Senanayaka', R P Palitha Karunapema ${ }^{2}$
}

Sri Lanka Journal of Diabetes, Endocrinology and Metabolism 2015; 5: 75-78

\begin{abstract}
Introduction: Non communicable diseases, mainly cardiovascular diseases and diabetes have a large but unappreciated negative impact on individuals, families and countries and as such a major barrier to human development. Early diagnosis of these hidden illnesses and achievement of treatment goals are essential in order to prevent complications.
\end{abstract}

Materials and methods: Population of 495 people above the age of 18 years who attended free health camps in Western province of Sri Lanka were screened for overweight, obesity, pre-diabetes, diabetes, hypertension and hyperlipidemia. Prevalence of above conditions was estimated. Treatment target achievement was assessed among patients with hypertension, diabetes mellitus and hyperlipidemia.

Results: The mean BMI was 23.41 (SD 3.96) in men. It was lower than that in women, 24.45 (SD 4.34). Prevalence of obesity was $35.3 \%$ in men and $43.7 \%$ in women and prevalence of overweight was $13.7 \%$ in men and $18.5 \%$ in women. The prevalence of diabetes was $28.0 \%$ for men and $13.5 \%$ for women and $16.5 \%$ of new patients with diabetes were identified by this screening. The prevalence of pre-diabetes was $51.3 \%$ for men and $44.2 \%$ for women. The prevalence of hypertension was $42.3 \%$ and out of that $37.9 \%$ were newly diagnosed by screening. Prevalence of hyperlipidemia was $52.2 \%$ and $48.5 \%$ of them were diagnosed by the screening. Treatment targets were achieved by only $15 \%$ of diabetics and $55 \%$ of patients with hypertension. Only $38 \%$ of previously diagnosed patients with hyperlipidemia achieved total cholesterol (TC) target and only $16.5 \%$ achieved low density lipoproteins (LDL) target.

Conclusion: The prevalence of major metabolic risk factors is high in the studied population and is higher than the previously reported prevalence. There is also a reasonably high percentage of undiagnosed patients with cardio-metabolic risk factors. Many patients with CVD risk factors are treated but remained inadequately controlled.

\section{Introduction}

Non communicable diseases (NCD) kill 38 million people worldwide each year (1). Almost three quarters of NCD deaths occur in low and middle income countries (1, 2, 3 and 4). Cardiovascular diseases (CVD) account for most NCD deaths (1). Raised blood pressure (BP), increased blood glucose, elevated blood lipids and obesity are the major risk factors which can lead to CVD.

Evidence shows that both the incidence and prevalence of type 2 diabetes mellitus has been rising in adults, children and adolescents in the developed countries such as United Kingdom (5). There is evidence showing both the incidence and prevalence of noncommunicable diseases are on the rise in Sri Lankan population as well $(6,7)$.

The rapid rise in NCD is predicted to impede poverty reduction initiatives in low income countries. To lessen the impact on individuals, families and the society, a comprehensive approach is needed to manage these NCDs. It is necessary to work together to diagnose these NCDs early and to treat properly in order to reduce the associated CVD risks as well as to promote the interventions to prevent these NCDs in the community. We believe that our study will fulfill this task to some extent. The objectives of our study were to determine the prevalence of metabolic risk factors; obesity, overweight, diabetes, pre-diabetes, hypertension and hyperlipidemia among people attended free health camps in the western province of Sri Lanka, to identify the percentage of these risk factors detected by screening and to assess the adequacy of the control of diabetes, hypertension and hyperlipidemia in treated patients.

\section{Method}

This is a cross sectional descriptive study done with the patients participated in free health camps that we conducted in three districts of Western province in Sri

${ }^{1}$ Sri Jayewardenepura general hospital, Nugegoda, Sri Lanka, ${ }^{2}$ Rehabilitation and rheumatology hospital, Sri Lanka. 
Lanka, namely Colombo, Gampaha and Kalutara. The Study was conducted following the approval obtained from the ethical committee of the Sri Jayewardenepura general hospital. Heath camps were conducted in temples and government schools after obtaining permission from relevant authorities. People were informed by distributing leaflets and on some occasions by announcing by loudspeakers. They were asked to come early morning after 12 hours of fast. All the participants of these health camps were recruited for the study. Pregnant women and individuals with physical and mental disabilities were excluded. A total number of 495 people attended free health camps in years 2013 and 2014 were analyzed.

\section{Measurements}

Height and weight were measured and BMI were calculated. Over weight (BMI 23-24.9) and obesity (BMI 25 or more) were determined. Blood pressure was measured. FBS, PPBS and lipid profile were done. Treatment goals were evaluated in accordance with the 2007 European guidelines on CVD prevention (8). Hypertension (systolic blood pressure $140 \mathrm{mmHg}$ or more and /or diastolic blood pressure $90 \mathrm{mmHg}$ or more and/or use of antihypertensive medications) diabetes mellitus (FBS 126mg/dl or more, PPBS200mg/dl or more) and prediabetes (FBS 100 mg/dl-125mg/dl, PPBS 140mg/dl-199mg/ dl), hyperlipidemia (TC more than 200mg/dl, LDL $160 \mathrm{mg} /$ $\mathrm{dl}$ or more and TG $150 \mathrm{mg} / \mathrm{dl}$ or more) were determined.

All data collectors underwent training for the specific tasks required for this study. They were trained to ensure standardization of measurement techniques, interviewing, sample collection and labeling.

The data were collected using pre-tested questionnaire, which consisted of four sections. First section included demographic data. Section two included previous diagnoses and risk factor analysis for noncommunicable diseases. The third section was to document height, weight, BMI, blood pressure and biochemical results. The fourth section was to document the follow up plan for new diagnoses detected.

\section{Anthropometry}

Height was measured using a stadiometer and recorded to the nearest 10th of the centimeter with the subject looking straight ahead and with the back against the vertical support of the instrument. Weight was measured without shoes or slippers on a digital scale.

\section{Blood pressure}

Blood pressure was measured in the seated position after the participants had rested for at least 5 minutes. The measurement was taken using the supported left arm at the heart level, using mercury column sphygmomanometer, whose measuring accuracy had been validated and it met the criteria of the British Hypertension Society. Two recordings were taken and the mean was used for analysis. In the event of variation of over $20 \mathrm{mmHg}$ between recordings, a third reading was done and the mean of the last two recordings was used.

\section{Collection of blood samples}

From individuals, after 12 hours of fast, $5 \mathrm{ml}$ of venous blood was drawn and collected to a sugar bottle for FBS estimation $(2 \mathrm{ml})$ and a plain bottle for lipid profile estimation $(3 \mathrm{ml})$. Thereafter, they were given a standard Sri Lankan breakfast and $2 \mathrm{ml}$ of venous blood was drawn after 2 hours to a sugar bottle for PPBS estimation. Qualified government medical laboratory technicians carried out biochemical analysis at the site. Results were delivered the same day and patients were then seen by medical officers.

\section{Patient education and referral for follow up}

All the participants were educated by using audiovisual presentations with regards to life style modification, including healthy eating, exercise and stress reduction, while they were waiting for blood results.

Newly diagnosed patients were referred to the dietitian who attended the health camps. Referral letters were given to attend local clinics for regular follow up.

Trained nurses educated the patients with overweight and obesity to reduce their weight. They were educated about the ideal body weight that they should achieve and maintain verbally as well as with written information leaflets.

Patients with pre-diabetes were advised about intensive life style modification with the aim of prevention or delaying the development of diabetes among them. They were advised regarding the need for yearly screening. People with more than 2 risk factors for developing diabetes were also advised about life style modification and they were advised to have 3 yearly screening as per guidelines.

\section{Results}

There were 102 men and 393 women in the sample and the male to female ratio was $1: 3.8$. The mean age of men was 53.7 years (SD 14.3) and that of women was 52.9 years. (SD 12.5). The mean BMI was $23.41 \mathrm{~kg} / \mathrm{m}^{2}$ (SD 3.96) in men. It was lower than that in women, $24.45 \mathrm{~kg} / \mathrm{m}^{2}$ (SD 4.34). Prevalence of obesity was $35.3 \%$ in men and $43.7 \%$ in women and prevalence of overweight was $13.7 \%$ in men and $18.5 \%$ in women.

The prevalence of diabetes was $28.0 \%$ for men and $13.5 \%$ for women, and $16.5 \%$ of diabetic patients were identified by screening. The prevalence of pre-diabetes was $51.3 \%$ for men and $44.2 \%$ for women. Out of that $16.4 \%$ had both impaired fasting glucose (IFG) and impaired glucose tolerance (IGT) (Table 2). The prevalence 
of hypertension was $42.3 \%$ and out of that $37.9 \%$ were newly diagnosed by screening (Table 2). Prevalence of hyperlipidaemia was $52.2 \%$ and $48.5 \%$ was diagnosed by screening. Out of which $18.7 \%$ had combined hyperlipidaemia and 55.2\% had isolated LDL elevation and 26.5\% had isolated hypertriglyceridaemia.

Treatment target were achieved by only $15 \%$ of the patients with diabetes and $55 \%$ of patients with hypertension. Only $38 \%$ of previously diagnosed patients with hyperlipidaemia achieved TC target and only $16.5 \%$ achieved LDL target.

Tabel 1. Mean values of BMI, FBS, PPBS, blood pressure and lipid profile

\begin{tabular}{lrc}
\hline Mean values & \multicolumn{2}{c}{ Total } \\
& Male & Female \\
\hline $\mathrm{BMI}\left(\mathrm{Kg} / \mathrm{m}^{2}\right)$ & 23.4 & 24.4 \\
$\mathrm{FBS}(\mathrm{mg} / \mathrm{dl})$ & 109.5 & 108.1 \\
$\mathrm{PPBS}(\mathrm{mg} / \mathrm{dl})$ & 138.2 & 130.1 \\
$\mathrm{SBP}(\mathrm{mmHg})$ & 131.8 & 127.5 \\
$\mathrm{DBP}(\mathrm{mmHg})$ & 82.4 & 78.3 \\
$\mathrm{TC} \mathrm{mg} / \mathrm{dl}$ & 200.7 & 215.7 \\
$\mathrm{LDL} \mathrm{mg} / \mathrm{dl}$ & 134.6 & 150.1 \\
TGmg/dl & 126.2 & 114.1 \\
\hline
\end{tabular}

Table 2. Cardiovascular risk factors

\begin{tabular}{lcc}
\hline & \multicolumn{2}{c}{ Total } \\
& Male & Female \\
\hline Underweight & 19.8 & 5.6 \\
Normal & 41.2 & 31.7 \\
Overweight & 13.7 & 18.9 \\
Obesity & 35.3 & 43.7 \\
Pre-diabetes & 51.3 & 44.2 \\
Diabetes & 36.2 & 26.2 \\
Hypertension & 44.2 & 41.8 \\
Total cholesterol & 44.7 & 59.9 \\
Triglyceride & 28.4 & 19.8 \\
LDL & 25.5 & 38.7 \\
Hyperlipidemia & 44.2 & 49.6 \\
\hline
\end{tabular}

\section{Discussion}

Our health camps were mainly attended by the females and the male representation was comparatively less. Cut off values for overweight and obesity were taken according to Asian classification (9). Diabetes and pre-diabetes were identified according to American Diabetes Association (ADA) guidelines issued in 2014 (10). Hypertension was diagnosed according to JNC 8 (11). Hyperlipidemia was classified according to ATP 111 guidelines (12).

The prevalence of obesity, diabetes and hypertension among both males and females has increased compared to 2005 data (13). A study done in 1997 has shown that the mean BMI of men were $20.5 \mathrm{~kg} / \mathrm{m}^{2}$ and $20.9 \mathrm{~kg} / \mathrm{m}^{2}$ for woman among 30-65 year old healthy adults (14). The mean BMI was $21.5 \mathrm{~kg} / \mathrm{m}^{2}$ for men and $23.3 \mathrm{~kg} / \mathrm{m}^{2}$ for women according to the study done in 2005 (13). Our study showed mean BMI of 23.41 and 24.45 for men and women respectively. Prevalence of obesity and overweight were $35.3 \%$ and $13.7 \%$ for men and $43.7 \%$ and $18.9 \%$ for women respectively. A comprehensive assessment of trends in BMI in 199 countries showed mean BMI and prevalence of overweight has increased since 1980 (15) and our data also shows the same trend.

Studies conducted among general population of Sri Lanka in the past has shown a low prevalence of hypertension and the prevalence of hypertension among adults of 25-64 years in the Matale district was found to be about $8 \%$ (16). A study done in four provinces of Sri Lanka in the age group of 30-65 years showed a hypertension prevalence of $18.8 \%$ for men and $19.3 \%$ for women (13). This study showed a moderately high overall prevalence of hypertension of $42.3 \%$ as defined by either systolic blood pressure more than $140 \mathrm{mmHg}$ or diastolic blood pressure more than $90 \mathrm{mmHg}$.

Data for the prevalence of pre-diabetes is limited. A cross sectional study done in 288 young Mexican adults (18-30 years) in 2005 showed $14.6 \%$ of prevalence of prediabetes (17). A study done in 2006 has shown an overall prevalence of pre-diabetes as $11.5(10.5-12.5 \%)$ among the Sri Lankan adult population (18). Our study showed 51.3\% prevalence in men and $44.2 \%$ in women. We diagnosed $16.5 \%$ of people with DM, $37.9 \%$ of people with hypertension, and $48.5 \%$ people with hyperlipidemia by screening, in this study.

Control of diabetes, hypertension and hyperlipidemia among patients diagnosed in the past was highly unsatisfactory. A study done in US population among known diabetics above the age of 20 years showed only $37 \%$ had HbAlc less than 7.0 , only $35.8 \%$ had blood pressure less than $130 / 80 \mathrm{mmHg}$, only $50 \%$ had total cholesterol less than $200 \mathrm{mg} / \mathrm{dl}$ (19). Another study done in Italy from June to December in 2000 showed that $48 \%$ of patients with diabetes had HbA1c level of 7.5 or more, and $77 \%$ had blood pressure above target values (that is above 140/90 $\mathrm{mmHg}$ in non-diabetics and above 130/ $80 \mathrm{mmHg}$ in diabetics) and $85 \%$ had total cholesterol level above $190 \mathrm{mg} / \mathrm{dl}$ (20). According to a study in 12 European countries in 2009 among patient with diabetes aged 50 years and more, only $36.7 \%$ has achieved the less than $6.5 \% \mathrm{HbA} 1 \mathrm{c}$ target. Only $38.8 \%$ has achieved the blood pressure target of less than $140 / 90 \mathrm{mmHg}$. Only $41.2 \%$ has 
attained both the total and LDL cholesterol target of less than $5 \mathrm{mmol} / 1$ and less than $3 \mathrm{mmol} / 1$ (21). In our study, $84.9 \%$ of patients with known diabetes had FBS more than $100 \mathrm{mg} / \mathrm{dl}$ and $74.6 \%$ had PPBS more than $140 \mathrm{mg} / \mathrm{dl}$. Blood pressure control was satisfactory only in 55.8\%. Only $39.8 \%$ of the previously diagnosed patients with hyperlipidemia had TC less than $200 \mathrm{mg} / \mathrm{dl}$ and $73.2 \%$ had TG less than $150 \mathrm{mg} / \mathrm{dl}$. Only $15.9 \%$ had LDL value less than $100 \mathrm{mg} / \mathrm{dl}$.

The EUROACTION study has shown that a nurseled, multi-disciplinary team approach can yield significant lifestyle improvements and risk factor reductions (22). Multifactorial treatment considering life style interventions and pharmacotherapy is the way forward in managing these NCDs.

\section{Conclusions}

These data showed that the prevalence of noncommunicable diseases is on the rise. A significant percentage of these diseases are undiagnosed. The high prevalence of prediabetes gives us a warning that we should intensify diabetes prevention programs, and this also gives us a prediction of the future of current diabetic epidemic. Achievement of targets among already diagnosed patients with above disease conditions is not satisfactory. Early detection and treatment of these conditions are cost effective and reduce the need for expensive interventions. There is a need for strengthening the primary care structure for early detection and timely treatment of these illnesses.

\section{Acknowledgements}

We acknowledge the voluntary contribution made by all the doctors, nurses, dietitian, laboratory technicians and orderly staff who participated in this study.

\section{References}

1. World Health Organization. Global status report on noncommunicable diseases - 2014.

2. Abegunde DO, Mathers CD, Adam T, Ortegon M, Strong $\mathrm{K}$. The burden and costs of chronic diseases in low-income and middle income countries. Lancet 2007; 370:1929-38.

3. Wang L, Kong L,Wu F, et al. preventing chronic diseases in china. Lancet 2005; 366:1821-4.

4. Reddy KS; Shah B, Varghese C, Ramadoss A. Responding to the threat of chronic diseases in India. Lancet 2005; 366; 1744-9.

5. Whiting DR,Guariguata L, Weil C, Shaw J. IDF diabetes atlas; global estimates of the prevalence of diabetes for 2011 and 2030. Diabetes Research and Clinical Practice $2011 ; 94 ; 311-21$.

6. Ministry of health. Sri Lanka Annual Health Bulletins. 2011.

7. P Katulanda, MHR Sheriff, and DR Matthews. The diabetes epidemic in Sri Lanka - a growing problem. Ceylon Medical Journal 2006; 51(1); 26-8.
8. Graham I, Atar D, Borch-Johnson K, et al. Fourth joint task force of the European Society of Cardiology and other societies on cardiovascular disease prevention in clinical practice. Euro J Cardiovasc prev Rehabill 2007; 14(2); 1-113.

9. Appropriate BMI for Asian populations and its implications for policy and intervention strategies. Lancet 2004; 363; 157-63. American Diabetes Association. Standards of medical care for patients with diabetes mellitus. Diabetes care 2014 ; 38; 31-93.

10. Paul A. James MD, Suzanne Opril MD, Barry L. Carter Pharm D, et al. 2014 Evidence based guidelines for the management of high blood pressure in adults. JAMA 2014; 311(5); 507-20.

11. National Cholesterol Education Programme (NCEP) Expert Panel on Detection, Evaluation and Treatment of High Blood Cholesterol in Adults. Executive summary of the third report of the NCEP JAMA 2001; 285; 2486-97.

12. Wijewardene K, Mohideen MR, Mendis S, Fernando DS, Kulathilaka T, Weerasekara D, Uluwitta P. Prevalence of hypertension, diabetes and obesity; baseline findings of a population based survey in four provinces in Sri Lanka. Ceylon Medical Journal 2005; 50(2); 62-70.

13. Nasser MACKA, Mendis S. the prevalence of obesity in a Sri Lankan Community Proceedings of the Sri Lanka. Association for the Advancement of Science, 1997; 41.

14. Finucane MM, Stevens GA, Cowan MJ, et al. National, regional, and global trends in BMI since 1980; systematic analysis of health examination surveys and epidemiological studies with 960 country years and 9.1 million participants. Lancet 2011; 377; 557-67.

15. Dhanapala S. Prevalence, Risk factors, Awareness, Treatment status of Hypertension in the District of Matale. MD Community Medicine Thesis. Postgraduate Institute of Medicine 1997.

16. Urena Bogarin, Hector R., Martinez Ramirez, Jose R TorresSanchez, et al. Prevalence of pre-diabetes in young Mexican adults in primary health care.

17. Katulanda P, Constantine GR, Mahesh JG, Sheriff MHR, Seneviratne RDA, Wijeratne S. Prevalence and projections of diabetes and pre-diabetes in adults in Sri Lanka - Sri Lanka Diabetes, Cardiovascular Study (SLDCS). Diabetic Medicine 2008; 25(9): 1062-9.

18. Sharon H, Saydah PhD, Judith Fradkin MD, Catherine C. Cowie, PhD. Poor control of risk factors for vascular disease among adults with previously diagnosed diabetes. JAMA 2004; 291(3); 335-42.

19. Roccatagliata D, Avanzini F, Monesi L, caimi V, et al. Collaborative group risk and prevention study. Is global cardiovascular risk considered in current practice? Treatment and control of hypertension, hyperlipidaemia and diabetes according to patient risk level. Vas Health and risk manag 2006; 2(4); 507-14.

20. Jose R. Banegas, Esther Lopez-Garcia, Jean Dallongeville, et al. Achievement of treatment goals for primary prevention of cardiovascular disease in clinical practice across Europe; the EURIKA study. European heart journal 2011; 32; 2143-52.

21. Wood DA, Kotseva K, Connolly S, et al. Nurse coordinated multidisciplinary family based cardiovascular disease prevention programme. Lancet 2008; 371; 1999-2012. 